\title{
The Influence of Microbial Endophytes/Epiphytes on Medicinal Plant Components
}

David J. Newman, DPHLL ${ }^{1 *}$

${ }^{1}$ Newman Consulting LLC, Wayne, PA 19087, USA

*• djnewman664@verizon.net

KEYWORDS: Endophytes; epiphytes; medicinal plants

\section{Introduction}

I have been invited by the Editor in Chief and the Editorial Board of the Journal to contribute an editorial piece on a topic concerning natural health products that was thought-provoking based on my recognized experience in this field. I decided to take some information from how Traditional Chinese Medicine (TCM), together with other medicinal plants from different cultures (Ayurvedic materials) were collected and used to produce medicinal treatments versus what is known today as to what the "bioactive components" are and what may have produced them.

In this short article I will show with some specific examples, the involvement of fungi and/or bacteria in the production of medicinal compounds isolated from plants (some reported to be medicinal, others not recognized as such); this being such that one could argue that in certain cases, the plant is nothing more than a host to a consortium of microbes that are heavily involved in the production of the compound(s) of interest.

\section{Discussion}

\section{Traditional Chinese Medicine (TCM)}

There are very specific requirements involved in harvesting a majority of TCM plants in China, (known as Daodi), that nowadays tend not always to be followed. Paraphrasing what was stated by Wang et al. [1] in 2019 "Daodi is a term unique to TCM and is reserved for medicinal plants cultivated in a specific geographical area with specified natural conditions and being harvested and processed following standards". It is stated in an ancient Materia Medica, the "Xin-Xiu-Ben-Cao" that the medical efficacy will be different if the medicinal material is not grown in its native environment. Thus, the ancient Chinese people were aware of the fact that geographical changes may influence the activity of herbal material used in TCM [2]. Thus, "Daodiclassified" medicinal plants, irrespective of disease treatment would be collected at certain times of the year, under specific weather conditions and frequently at a specific altitude. At the time that these provisions were made (anywhere from one to two thousand plus years ago) the concept of microbes (endophytes or epiphytes) whether eukaryotic or prokaryotic were completely unknown. It must be remembered that the presence of "animacules" was not shown until the middle 1600s and was not believed for many years after that [3].

Using information from specialists at the Chinese University in Hong Kong working with a multinational group that included Western physicians, pharmacologists and chemists, defined TCM materials were obtained for further work-up as to bioactive chemical components, bearing in mind the Daodi concepts [4]. Thus these comparative TCM collections had the identical plant collected not only where the TCM practitioners suggested, but also collections were made at different altitudes and climatic conditions, with the ultimate aim of all samples subsequently being treated in a similar manner. Preliminary results showing the differences in antitumor activities were published by the NCI group involved in 2019, and all samples are available for further work by others subject to suitable intellectual property provisions [5].

Evidence of such effects outside of China can be seen from initial results that the Natural Products Branch of 
the US National Cancer Institute had when working with plant samples from Africa. An extract from a collection of $1 \mathrm{~kg}$ (air-dried weight) plant sample gave an interesting result in the NCI's antitumor screens. Following chemical workup, and the requirement for more plant sample, a recollection at the same spot was made by the original collectors but was inactive in the same screen and did not contain the same active chemical structures. On subsequent collection data analysis, it was realized that the second collection was not made under the same climatic conditions as the first collection.

What is also significant is that today, modern TCM investigators will take the TCM mixtures as defined in various herbals, and then use metabolomic techniques in order to identify the bioactive components, with the aim of tracing the "source(s)", in order to formally systematize "modern" TCM. A review of current methods and results was published by the author in 2020 following a request from the Chinese Pharmacological Society [6].

\section{Fungal Endophytes from the Neem Tree}

The neem tree is extremely well known in India and some other parts of Asia to be the source of "medicinal preparations" that can be used to deter insects (and also have indirect antimalarial properties by killing the anopheles mosquito). In 2012, Kusari et al. [7] reported the isolation of azadirachtins A and B $[\mathbf{1}, \mathbf{2}]$ from the endophytic fungus Eupenicillium parvum that had been isolated from the tree. In addition, though not used as a source of antitumor agents or antibacterial agents (though some of these activities have been "implied" by users of Neem-derived preparations), in the same time frame, reports of the isolation of the naphthaquinone antibacterial agent Javanicin [3] from the Neem fungal endophyte Chloridium sp. were reported by Kharwar
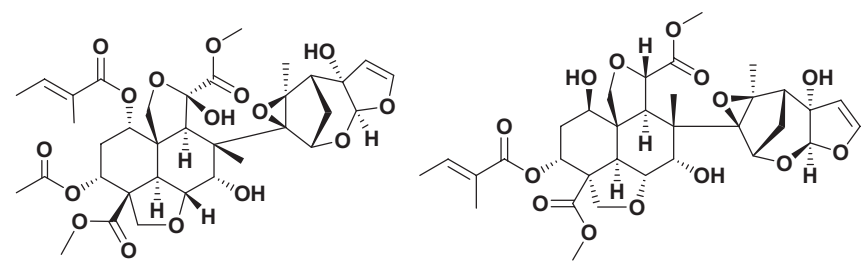

1. Azadirachtin A

2. Azadirachtin B
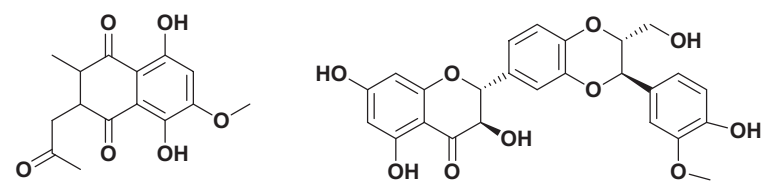

3. Javanicin et al. [8]. If further reading as to the listing of Indian medicinal plants and their properties is desired, the review by Mohanraj et al. published in 2018 can be consulted [9].

\section{Recent Reports/Reviews on Endophytes and Bioactive Secondary Metabolites}

\section{Endophytes from the Milk Thistle Silybum marianum}

In 2014 and 2015, the Oberlies and Cech groups at the University of North Carolina, Greensboro, published two papers on fungal endophytes isolated from the medicinal plant known colloquially as the "Milk Thistle" (Silybum marianum). The 2014 report dealt with the production of the bioactive compounds known as the silybins [4] originally isolated from the plant, which had been used for centuries as a "treatment" for liver disorders with the compounds themselves were listed as hepatoprotectants. They found that the compounds were produced by an endophytic fungus (Aspergillus iizukae) that when fermented required a sterile wash from the plant's leaves to enable subcultures for continue to produce the compounds [10].

Following up on the fungal endophyte population isolable from this medicinal plant, work published the following year demonstrated that the plant hosted a minimum of 25 different endophytic fungi (from genomic analyses), produced 58 known secondary metabolites and 4 novel secondary metabolites, using solid-state fermentation processes (which could be considered a mimic of the plant system) with some demonstrating previously unrecognized antitumor activity on cell lines [11].

\section{Recent General Reviews of Endophytes from Medicinal Plants}

In 2015 and in 2018, two excellent review articles that demonstrate the "probable" production of the bioactive compounds (where the use of the plants as medicinal agents was implied?) have been published. The first was the general overview by Ludwig-Muller in 2015, [12] asking if plants and endophytes were "equal partners" in production of bioactive agents? By contrast, the second review in 2018 by Chutulo and Chalannavar was directed solely at the large number of bioactive materials produced by endophytic fungi isolated from the Neem tree [13].

Then in 2020, Cruz et al. [14] published an excellent review of the bioactive secondary metabolites isolated from fungi obtained from members of the Rubiaceae, a plant family that contains a very significant number of 
plants considered to be "medicinal". This review which is in the open access "Journal of Fungi" is up to date as of the early part of 2020 and should definitely be read, as it shows the number and variety of molecules that were found.

To these can be added a review commissioned for a special issue of Planta Medica on endophytic microbes and their bioactive metabolites [15].

\section{Conclusions}

Hopefully these few but carefully chosen examples indicate that the comment made earlier, that plants may, in a number of cases, be nothing more than a "container" in which both prokaryotic and eukaryotic microbes are actually producing bioactive agents. This can be considered as a two-way street in that the plant obtains "protective chemicals" in exchange for a "physical protection" from other predators. Then man and animals utilized their metabolites for medicinal usage.

\section{Ethics Approval and/or Participant Consent}

This was a commissioned review that did not involve any participants.

\section{Authors' Contributions}

DJN: made contributions to the design of the study, collected and analysed data, drafted the manuscript, and gave final approval of the version to be published.

\section{References}

[1] Wang J, Sasse A, Sheridan H. Traditional Chinese medicine: From aqueous extracts to therapeutic formulae. Plant Extracts. Rijeka, Croatia: IntechOpen; 2019. https://doi.org/10.5772/intechopen.85733

[2] Zhao Z, Guo P, Brand E. The formation of daodi medicinal materials. J Ethnopharm. 2012;140:476-81. https:// doi.org/10.1016/j.jep.2012.01.048

[3] Lane N. The unseen world: reflections on Leeuwenhoek (1677) 'Concerning little animals'. Phil Trans R Soc B. 2015;370:20140344. https://doi.org/10.1098/ rstb.2014.0344

[4] Eisenberg DM, Harris ES, Littlefield BA, Cao S, Craycroft JA, Scholten R, et al. Developing a library of authenticated Traditional Chinese Medicinal (TCM) plants for systematic biological evaluation-rationale, methods and preliminary results from a Sino-American collaboration. Fitoterapia. 2011;82:17-33.

[5] He M, Grkovic T, Evans JR, Thornburg CC, Akee RK, Thompson JR, et al. The NCl library of traditional Chinese medicinal plant extracts-Preliminary assessment of the NCI-60 activity and chemical profiling of selected species. Fitoterapia. 2019;137:104285. https:/doi. org/10.1016/j.fitote.2019.104285

[6] Newman DJ. Modern traditional Chinese medicine: Identifying, defining, and usage of traditional Chinese components". Adv Pharmacol. 2020;87:113-58. https:// doi.org/10.1016/bs.apha.2019.07.001

[7] Kusari S, Verma VC, Lamshoeft M, Spiteller M. An endophytic fungus from Azadirachta indica A. Juss. that produces azadirachtin. World J Microbiol Biotechnol. 2012;28:1287-94.

[8] Kharwar RN, Verma VC, Kumar A, Gond SK, Harper JK, Hess WM, et al. Javanicin, an antibacterial naphthaquinone from an endophytic fungus of neem, Chloridium sp. Curr Microbiol 2009;58:233-8.

[9] Mohanraj K, Karthikeyan BS, Vivek-Ananth RP, Chand RPB, Aparna SR, Mangalapandi P, et al. IMPPAT: A curated database of Indian medicinal plants, phytochemistry and therapeutics. Sci Rep. 2018;8:4329. https://doi.org/10.1038/s41598-018-22631-z

[10] El-Elimat T, Raja HA, Graf TN, Faeth SH, Cech NB, Oberlies NH. Flavonolignans from Aspergillus iizukae, a fungal endophyte of milk thistle (Silybum marianum). J Nat Prod. 2014;77:193-9. https://doi.org/10.1021/ np400955q

[11] Raja HA, Kaur A, El-Elimat T, Figueroa M, Kumar R, Deep $G$, et al. Phylogenetic and chemical diversity of fungal endophytes isolated from Silybum marianum (L) Gaertn. (milk thistle). Mycology. 2015;6:8-27. https://doi.org/ 10.1080/21501203.2015.1009186

[12] Ludwig-Muller J. Plants and endophytes: equal partners in secondary metabolite production? Biotechnol Lett. 2015;37:1325-34. https://doi.org/10.1007/ s10529-015-1814-4

[13] Chutulo EC, Chalannavar RK. Endophytic mycoflora and their bioactive compounds from Azadirachta Indica: A comprehensive review. J Fungi. 2018;4:42. https://doi. org/10.3390/jof4020042

[14] Cruz JS, da Silva CA, Hamerski L. Natural products from endophytic fungi associated with Rubiaceae species. J Fungi. 2020;6:128. https://doi.org/10.3390/jof6030128

[15] Newman DJ, Cragg GM. Plant endophytes and epiphytes; Burgeoning sources of known and "unknown" cytotoxic and antibiotic agents? Planta medica. 2020 86:891-905. https://doi.org/10.1055/a-1095-1111 


\section{Article Information}

Managing Editor: Pierre Haddad, Kieran Cooley

Article Dates: Received Apr 22 21; Accepted May 03 21; Published May 2421

\section{Citation}

Please cite this article as follows:

Newman DJ. The Influence of Microbial Endophytes/Epiphytes on Medicinal Plant Components. Journal of Natural Health Product Research. 2021 May 24: 1(3). https://jnhpresearch.com/index.php/jnhpr/article/view/18

DOI Link: https://doi.org/10.33211/jnhpr.18

\section{Copyright}

(c) David J. Newman. (2021). Published first in the Journal of Natural Health Product Research. This is an open access article distributed under the terms of the Creative Commons Attribution License (https://creativecommons.org/licenses/by/4.0/), which permits unrestricted use, distribution, and reproduction in any medium, provided the original work, first published in the Journal of Natural Health Product Research, an NHP Publications journal, is properly cited. The complete bibliographic information, a link to the original publication on https://www.jnhpresearch.com, as well as this copyright and license information must be included.

Journal of Natural Health Product Research
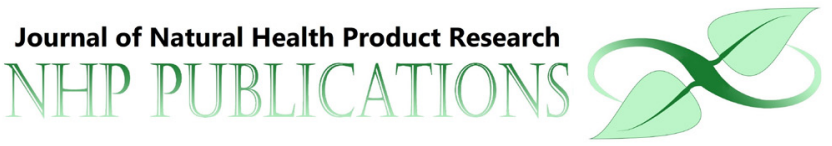

Canadà̀

Does the safety, efficacy, and quality of natural health products matter to YOU? Submit your research article to the Journal of Natural Health Product Research!

Pre-submission inquiries? Send us an email at editorial.office@jnhpresearch.com Facebook, Twitter and LinkedIn: @NHPPublications 